\title{
DOSES OF EPINEPHRINE CAUSING ARRHYTHMIA DURING ENFLURANE, METHOXYFLURANE AND HALOTHANE ANAESTHESIA IN DOGS
}

\author{
Edwin S. Munson and William K. Tucker
}

THE Association of cardiac arrhythmias with adrenergic drugs and anaesthetic agents has received extensive study. While halothane, cyclopropane and chloroform are among those clearly implicated as "sensitizing" the myocardium, studies of newer inhalation anaesthetic agents have shown relatively less arrhythmogenic potential. However, quantitation of arrhythmogenic action is difficult because, in most instances, studies have been conducted by invesitgators using different techniques. We have reported recently the comparative effects of the arrhythmic doses of four vasopressors during equivalent levels of isoflurane and halothane anaesthesia in dogs. ${ }^{1}$ The results obtained for epinephrine were similar to those described by Joas and Stevens ${ }^{2}$ in their evaluation of halothane and isoflurane. In the present study, we have used a similar methodology to evaluate the arrhythmogenicity of two other halogenated ethers, enflurane and methoxyflurane. For comparison, similar studies also were performed on the same animals during halothane anaesthesia.

\section{Methods}

Fifteen experiments were performed on five non-premedicated male mongrel dogs, ranging in weight from 13.4 to $18.0 \mathrm{~kg}$ (mean $16.0 \mathrm{~kg}$ ). Following induction of anaesthesia with the agent under study, each animal's trachea was intubated with a cuffed tracheal tube without the use of muscle relaxants. The methodology employed is shown in Figure 1. Ventilation was maintained with a volume-limited ventilator at approximately 4 per cent end-tidal $\mathrm{CO}_{2}$ concentration as determined by a Godart capnograph. Femoral, arterial and forelimb venous cannulae were placed percutaneously. Phasic and mean arterial pressures were recorded on a direct-writing oscillograph. Each animal was placed supine on a warming blanket and oesophageal temperatures were measured with a thermistor probe. The ECG (lead II) recorded cardiac rate and rhythm.

Each animal was anaesthetized with enflurane, methoxyflurane and halothane on separate occasions, intervals ranging from seven to fourteen days. End-tidal (alveolar) enflurane and halothane concentrations were monitored with a Beckman LB-2 infrared halothane analyzer. The analyzer was calibrated against gas mixtures stored in cylinders. The composition of these mixtures was analyzed by

From the Department of Anesthesiology, University of Florida College of Medicine, Box 721 , J. Hillis Miller Health Center, Gainesville, Florida 32610.

This work was supported in part by USPHS Grant GM00427-12.

The research described in this report involved animals maintained in animal care facilities fully accredited by the American Association for the Accreditation of Laboratory Animal Care. Address all correspondence to Dr. Munson. 


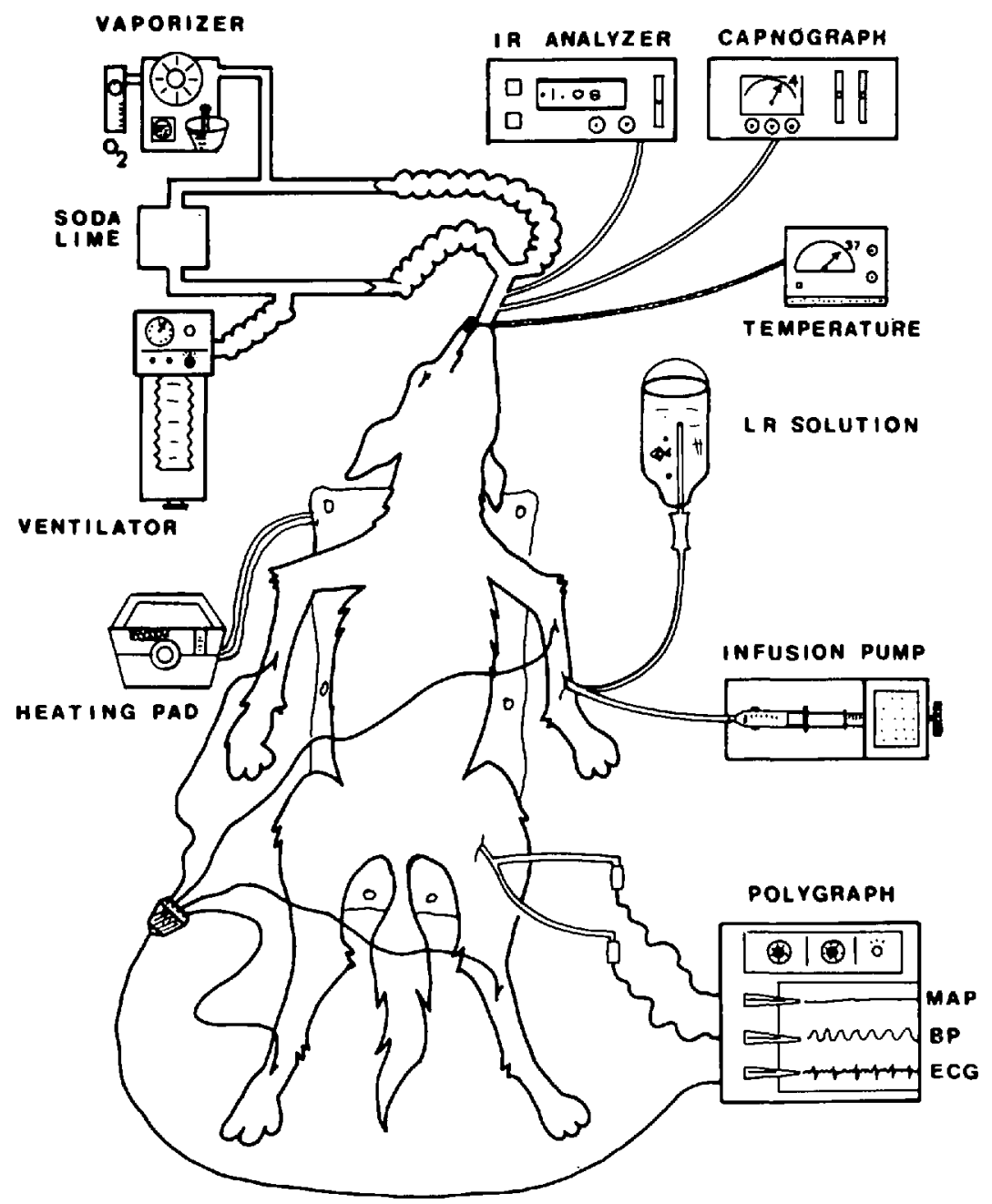

FIGURE 1. A schematic diagram of the methodology employed. MAP $=$ Mean arterial pressure.

gas chromatography. ${ }^{3}$ Calibration of the analyzer was made in the presence of $\mathrm{CO}_{2}$ to eliminate the cross-over effect of this gas. After induction of anaesthesia, inspired anaesthetic concentrations were reduced until end-tidal values remained stable at a level of approximately 1.2 MAC for a period of at least 40 minutes. Equivalent MAC values for the dog are 2.2 per cent for enflurane, ${ }^{4}$ and 0.87 for halothane. ${ }^{5}$ Since the measurement of end-tidal methoxyflurane concentrations tends to overestimate arterial levels, ${ }^{6}$ determination of anaesthetic depth was made by gas chromatographic analysis of arterial methoxyflurane content. ${ }^{7}$ This equilibration method determines anaesthetic content and blood/gas partition coefficient and allows for the calculation of the corresponding alveolar tension (concentration). The MAC value for methoxyflurane in dogs is 0.23 per cent. ${ }^{5}$ Maintenance of constant end-tidal levels of methoxyflurane was achieved with the infrared analyzer adjusted to maximum sensitivity. While this technique did 
not allow for the determination of an absolute level of anaesthesia, the depth achieved was held constant for a period ranging from 75 to 130 minutes prior to arterial sampling.

After the anaesthetic level had been established, arterial blood samples were obtained for the determination of $\mathrm{Pa}_{\mathrm{O}_{2}}, \mathrm{~Pa}_{\mathrm{CO}_{2}}$, and $\mathrm{pH}$, using a radiometer BMS-3 blood gas analyzer. In each experiment, epinephrine was administered intravenously at a rate of $2.5 \mu \mathrm{g} / \mathrm{kg} / \mathrm{min}$ by constant volume infusion pump. Drug infusions were continued until two or more premature ventricular contractions occurred within 20 seconds. If no arrhythmia occurred, the epinephrine infusion was maintained until the mean arterial pressure had reached a plateau value and showed no further increase for a three-minute period. In most animals this level of hypertension represented a mean arterial pressure approximately twice the control value. The arrhythmogenic dosage of epinephrine was calculated as a function of this time and expressed in $\mu \mathrm{g} / \mathrm{kg}$ body weight. After termination of the epinephrine infusion, animals were observed for the development of arrhythmias for at least 15 minutes. Frequencies of responses were analyzed by the calculation of binomial distribution and other data utilizing Student's t-test.

\section{Results}

The arrhythmogenic doses of epinephrine and circulatory responses for all experiments are shown in Table I. Mean $( \pm$ SD) epinephrine dosage for halothane was $4.6 \pm 3.3 \mu \mathrm{g} / \mathrm{kg}$. Corresponding values for enflurane and methoxyflurane were significantly greater $(\mathrm{p}<0.05), 17.1 \pm 7.2$ and $14.0 \pm 4.7 \mu \mathrm{g} / \mathrm{kg}$, respectively. In addition, the mean arterial pressure at which arrhythmias occurred during halothane anaesthesia was also significantly less than observed with the other anaesthetics. No significant difference in heart rate was observed during epinephrine infusion between any of the anaesthetics studied. While epinephrine infusion induced premature ventricular contractions in every animal during halothane anaesthesia, only one animal during enflurane, and one other animal during methoxyflurane anaesthesia showed ventricular irritability. $\mathrm{Pa}_{2}$, acid-base, tem-

TABLE I

Arrhythmogenc Doses of Epinephrine and Circulatory Responses in 5 Dogs During Enflurane, Methoxyflurane and Halothane Anaesthesia

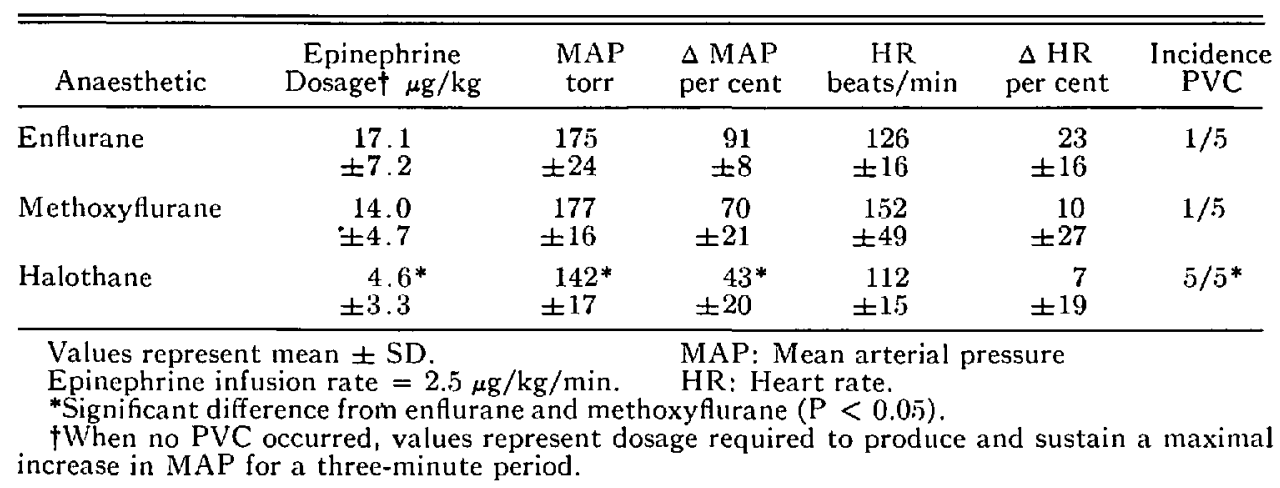


TABLE II

Acid-base, Temperature and Anaesthetic Depth Data for 5 Dogs During Enflurane, Methox yflurane and Halothane Anaesthesia

\begin{tabular}{lccc}
\hline & Enflurane & Methoxyflurane & Halothane \\
\hline Pa (torr) & 41.0 & 38.5 & 41.2 \\
& \pm 4.7 & \pm 5.1 & \pm 2.2 \\
Base Deficit (mEq/L) & 1.6 & 2.9 & 2.0 \\
& \pm 2.9 & \pm 0.7 & $\pm \mathbf{1 . 7}$ \\
Temperature (C) & 37.0 & 37.3 & 37.2 \\
& \pm 0.2 & \pm 0.6 & \pm 0.5 \\
Alveolar Concentration & 2.73 & $0.16^{*}$ & 1.02 \\
(per cent) & \pm 0.02 & \pm 0.01 & \pm 0.01 \\
Relative Depth of Anaesthesia & 1.24 & 0.70 & 1.18 \\
(MAC) & & & \\
\hline
\end{tabular}

Values represent mean $\pm \mathrm{SD}$.

*Calculated from arterial levels (see text).

perature, and anaesthetic depth measurements for each group are shown in Table II. $\mathrm{Pa}_{\mathrm{O}_{2}}$ values in each animal were maintained above 385 torr and all animals survived the experiments described.

\section{Discussion}

The arrhythmogenic dose of epinephrine during relatively light levels ( 1.2 MAC) of halothane anaesthesia is similar to previous reports. ${ }^{1,2,8}$ Joas and Stevens ${ }^{2}$ found that the mean dose of epinephrine causing arrhythmias in awake dogs was $36 \mu \mathrm{g} / \mathrm{kg}$ and this clearly indicates that our epinephrine dosage of 4.6 $\mu \mathrm{g} / \mathrm{kg}$ during halothane anaesthesia represents a "sensitizing" or "potentiating" phenomenon. Evidence for a similar action of methoxyflurane is less well-documented. While Jacques and Hudon" reported that methoxyflurane did not "sensitize" the myocardium to epinephrine, Bamforth et al. ${ }^{10}$ found methoxyflurane "sensitization" similar to chloroform, but less than that observed with cyclopropane.

Unfortunately, data for a comparative evaluation of enflurane and methoxyflurane are not available because most investigators either evaluated these anaesthetics separately or have utilized varying experimental methodologies. While enflurane has been reported by some ${ }^{11,12}$ to "sensitize" the myocardium, a comparative evaluation of enflurane and methoxyflurane in beagles by Byles et $a l .{ }^{13}$ found cardiac irritability with both anaesthetics to be similar and signifcantly less as compared with halothane. Similar observations have been made in unpremedicated goats anaesthetized with these anaesthetics. ${ }^{14}$ Numerous clinical reports attest to the relative safety of epinephrine during methoxyflurane and enflurane anaesthesia and Crout and Brown ${ }^{15}$ have recommended the use of methoxyflurane in the management of pheochromocytoma. Johnston and Eger ${ }^{16}$ reported that the arrhythmogenic threshold to epinephrine following nasal submucosal injection in man was 3.6 times greater during enflurane and isoflurane than at equivalent levels of halothane anaesthesia.

Our anaesthetic technique resulted in comparable levels of enflurane and halo- 
thane anaesthesia (Table II). However, equivalent levels of methoxyflurane were underestimated by about 40 per cent. We do not believe that the failure to establish equivalent levels of methoxyflurane anaesthesia has influenced our results significantly. Although North et al. ${ }^{17}$ reported severe epinephrine-induced arrhythmia to be "infrequent" during light (eyelid reflex present) methoxyflurane anaesthesia, Joas and Stevens ${ }^{2}$ noted no correlation between depth of halothane, fluroxene and isoflurane anaesthesia and the occurrence of epinephrine-induced arrhythmias. Our methoxyflurane animals were sufficiently depressed to tolerate the procedure described without the appearance of movement or reflex responses.

The relation of anaesthetics, adrenergic agents and increased arterial blood pressure on myocardial automaticity is well known. ${ }^{18}$ During halothane anaesthesia the dose of epinephrine which produced arrhythmias increased mean arterial pressure an average of 40 per cent above control values. In contrast, during methoxyflurane and enflurane anaesthesia epinephrine infusion produced significantly higher $(p<0.05)$ mean arterial pressures before the onset of ventricular irritability (one animal in each group developed PVC). Our previous studies with isoflurane ${ }^{1}$ failed to demonstrate any cardiac arrhythmias when epinephrine was administered at the same rate $(2.5 \mu \mathrm{g} / \mathrm{kg} / \mathrm{min}$.) However, when the epinephrine infusion rate was increased to $10 \mu \mathrm{g} / \mathrm{kg} / \mathrm{min}$, premature ventricular contractions developed in each animal but only when the mean arterial pressure rose to between 170 and 225 torr (mean increase of 113 per cent). This suggests that cardiac arrhythmias could most likely be produced during methoxyflurane and enflurane anaesthesia if epinephrine were administered at a rate sufficient to produce this same marked elevation in systemic arterial pressure.

Our findings, when combined with those of others, ${ }^{12,13.14,16}$ permit the quantitative evaluation of the compatibility of epinephrine with several halogenated inhalation anaesthetic agents. Halothane and epinephrine are least compatible, clearly showing "sensitization." Isoflurane and fluroxene are the most compatible. On a continuum of epinephrine compatibility, enflurane and methoxyflurane lie somewhere between these other agents. In clinical practice the administration of epinephrine during enflurane or methoxyflurane anaesthesia would be safe if the guidelines recommended by Katz et al. ${ }^{19}$ for halothane are applied, namely, if the total dose of epinephrine is restricted to less than $300 \mu \mathrm{g} / 70 \mathrm{~kg} / \mathrm{hour}$ and if adequate ventilation is maintained.

\section{SUMMary}

The arrhythmogenic dosage of epinephrine, administered by constant intravenous infusion, was measured in five dogs during enflurane, methoxyflurane and halothane anaesthesia. While premature ventricular contractions were observed in only one of five dogs with enflurane and methoxyflurane, epinephrine-induced arrhythmias were seen in all animals during halothane anaesthesia. Epinephrine dosage and the resultant increase in mean arterial blood pressure at which arrhythmias occurred during halothane anaesthesia were significantly less $(\mathrm{p}<$ 0.05 ) than with the other anaesthetics. These observations indicate that enflurane and methoxyflurane, as compared to halothane, possess relatively less arrhythmo- 
genic potential as sensitizing agents in the presence of increased circulating catecholamines.

\section{RÉSUMÉ}

Chez cinq chiens, nous avons calculé la dose arythmogénique d'épinéphrine en perfusion intra-veineuse au cours de l'anesthésie à l'enflurane, au méthoxyflurane et à l'halothane. Alors que des extrasystoles ventriculaires furent observées chez un seul des cinq chiens sous enflurane et sous méthoxyflurane, l'épinéphrine a provoqué des arythmies chez tous les chiens soumis à l'halothane. La dose d'épinéphrine et l'augmentation subséquente de la T.A. moyenne ayant provoqué des arythmies furent significativement moins élevées $(p<0.5)$ avec l'halothane qu'avec les autres agents. Ces observations démontrent que l'enflurane et le méthoxyflurane, comparativement à l'halothane, possèdent relativement moins de pouvoir arythmogénique en présence de catécholamines circulantes élevées.

\section{ACKNOWLEDGMENT}

The authors gratefully acknowledge the technical assistance of William J. Embro in the conduct of the experiments and for the preparation of the Figure.

\section{REFERENCES}

1. TUCKER, W.K., Rackstein, A.D., \& Munson, E.S. Comparison of arrhythmic doses of adrenaline, metaraminol, ephedrine and phenylephrine during isoflurane and halothane anaesthesia in dogs. Brit. J. Anaesth. 46: 392 (1974).

2. JoAs, T.A. \& STEvens, W.C. Comparison of the arrhythmic doses of epinephrine during Forane, halothane and fluroxene anaesthesia in dogs. Anesthesiology 35: 48 (1971).

3. Tham, M.K., HafDY, C.A., \& ShaH, D.O. Gas-chromatographic method using surfactants for analysis of volatile anaesthetics in blood. Anesthesiology 37:647 (1972).

4. Eger, E.I., II, Lundgren, C., Minier, S.L., \& Stevens, W.C. Anaesthetic potencies of sulfur hexafluoride, carbon tetrafluoride, chloroform and Ethrane in dogs. Anesthesiology 30: 129 (1969).

5. Eger, E.I., II, Brandstater, B., Saldman, L.J., Regan, M.J., Severinghaus, J.W., \& MUNSoN, E.S. Equipotent alveolar concentrations of methoxyllurane, halothane, diethyl ether, fluroxene, cyclopropane, xenon and nitrous oxide in the dog. Anesthesiology 26: $771(1965)$.

6. EGER, E.I., II \& BAHLMAN, S.H. Is the end-tidal anaesthetic partial pressure an accurate measure of the arterial anaesthetic partial pressure? Anesthesiology 35: 301 (1971).

7. Finx, B.R. \& Morrkawa, K. A simplified method for the measurement of volatile anaesthetics in blood by gas chromatography. Anesthesiology 32; 451 (1970).

8. TUCKER, W.K. \& MUNSON, E.S. Effects of succinylcholine and d-tubocurarine on epinephrine-induced arrhythmias during halothane anaesthesia in dogs. Anesthesiology 42 : 41 (1975).

9. JACQUES, A. \& HUdon, F. Effect of epinephrine on the human heart during methoxyflurane anaesthesia. Can. Anaes. Soc. J. 10: 53 (1963).

10. Bamforth, B.J., Snebecker, K.L., Kraemer, R., \& Orth, O.S. Effect of epinephrine on the dog heart during methoxyflurane anaesthesia. Anesthesiology 22: 169 (1961).

11. McDowell, S.A., Hall, K.D., \& StepHEN, C.R. Difluoromethyl 1,1,2-trifluoro-2-chloroethyl ether: experiments on dogs with a new inhalational anaesthetic agent. Brit. J. Anaesth. 40: 511 (1968).

12. Virtue, R.W., Lund, L.O., Phelps, McK., Je, Vogel, J.H.K., Beckwtt, H., \& Heron, M. Difluoromethyl 1,1,2-trifluoro-2-chloroethyl ether as an anaesthetic agent. Can. Anaesth. Soc. J. 13: 233 (1966).

13. Byles, P.H., Dobkin, A.B., Ferguson, J.H., \& Levy, A.A. Forane (Compound 469): 2. 
Biochemical effects of repeated administration to animals, response to bleeding, and compatibility with epinephrine. Can. Anaesth. Soc. J. 18: 387 (1971).

14. Zahed, B., Miletich, D.J., Ivankovich, A.D., Alghecit, R.F., Toyooka, E., \& Massau, B. Comparison of the arrhythmic doses of epinephrine and dopamine during enflurane, fluroxene, halothane and methoxyflurane anaesthesia. Abstracts of Scientific Papers, 1974 Annual Meeting, American Society of Anesthesiologists, p. 55.

15. Crout, J.R. \& Brown, B.R., JR. Anesthetic management of pheochromocytoma: the value of phenoxybenzamine and methoxyflurane. Anesthesiology 30:29 (1969).

16. JohNSTON, R.R. \& EGER, E.I., II. A comparative interaction of epinephrine with halothane, enflurane and isoflurane in man. Abstracts of Scientific Papers, 1974 Annual Meeting, American Society of Anesthesiologists, p. 55.

17. North, W.C., KNox, P.R., \& STEPHEN, C.R. Cardiac arrhythmias with methoxyflurane. Excerpt Med. Internat. Congress Series \#48, 22nd International Congress of Physiological Sciences, Leiden, 1962, p. 1204.

18. KATZ, R.L. \& Epstein, R.A. The interaction of anaesthetic agents and adrenergic drugs to produce cardiac arrhythmias. Anesthesiology 29: 763 (1968).

19. Katz, R.L., Matreo, R.S., \& Papper, E.M. The injection of epinephrine during general anaesthesia with halogenated hydrocarbons and cyclopropane in man. 2. Halothane. Anesthesiology 23: 597 (1962). 